\section{Community-based Health Research: Issues and Methods}

\author{
Daniel S. Blumenthal and Ralph J. \\ Diclemente, editors
}

\section{Springer Publishing Company, New York, New York ISBN: 0-8261-2025-3}

Pages: 240, Price: U.S.\$39.95

So many, 11 of 14 , contributors to this volume are from the Atlanta area that I expected this book to speak with a Southern drawl. That it does not attests to how much this metropolis, growing in kudzu-fashion, has changed. This element of profound change is also a major motif in the 10 chapters collected by the editors to promote community-based health research as a mechanism for addressing historic wrongs.

The book is aptly titled and subtitled. Former Surgeon General David Satcher writes in a concise but illuminating foreword, "Community-based research is where medicine, public health, and science meet.” In the opening chapter, Daniel Blumenthal and Elleen Yancey herald the arrival of a "new paradigm" in which community members become full partners with "culturally competent" researchers. To them, community-based research is population centered, prevention focused, multidisciplinary, collaborative, enlightening, and empowering. Caswell Evans follows by adding "evidence-based" assessments, findings, and guidance to the mix. In chapter 3, Bill Jenkins, Camara Jones, and Blumenthal address some of the ethical issues related to community-based research by describing, analyzing, and drawing lessons from the Tuskegee syphilis study. Culturally and linguistically diverse voices from the community are heard in chapter 4 .
Attention shifts from issues to methods in the last 6 chapters of the book. In textbook fashion, Nabih R. Asal and Laura A. Beebe distinguish observational studies from experimental designs in chapter 5 and remind the reader of the importance of person, place, and time in epidemiologic investigations. The strengths and weaknesses of the Behavioral Risk Factor Surveillance System are illustrated by Deborah Holtzman in chapter 6. Qualitative research methods are described in chapter 7 and applied to a case study of 45 AfricanAmerican, female crack-cocaine users in chapter 8. Community intervention trials are introduced and a half dozen are reviewed in chapter 9. Then the book rather abruptly ends with a short chapter on cardiovascular risk-reduction community intervention trials.

Instructors looking for a graduatelevel textbook may find this recent addition to the preventive medicine literature incomplete. It fails to link community-based research with theories of social and cultural change; the principles and practices of community mobilization; and the identification, development, implementation, and evaluation of culturally competent interventions. The editors have produced an adequate introduction to community-based research issues and methods, but a concluding section that serves to pull all the components together would put additional copies of this publication in college bookstores.

\section{William W. Darrow*}

*Florida International University, North Miami, Florida, USA

Address for correspondence: William W. Darrow, Robert R. Stempel School of Public Health, Florida International University, 3000 NE 151st St, TR-7, North Miami, Florida 33181-3600, USA; fax: 305-919-5673; email: darroww@fiu.edu

\section{The Pneumococcus}

\author{
Elaine I. Tuomanen, Timothy $\mathbf{J}$. \\ Mitchell, Donald A. Morrison, and \\ Brian G. Spratt, editors
}

\section{Washington: American Society for Microbiology Press; 2004 \\ ISBN: 1-55581-297-X}

Pages: 466, Price: U.S.\$115.95

Streptococcus pneumoniae, known as the pneumococcus, remains an important pathogen in spite of tremendous advances in medical care. Globally, as many as 1 million children die of pneumococcal infections each year, nearly all in developing countries. Pneumococcal disease is also common in children in industrialized countries, although in those settings nearly all such deaths occur in older adults or adults with chronic medical conditions. Given its place near the top of the list of killer bacteria, pneumococcus is a focus of numerous researchers around the world. A new book, The Pneumococcus, edited by Elaine Tuomanen et al., is the latest effort to summarize the state of research on the organism.

The book begins by providing a well-thought-out answer to a basic question-what is a pneumococcus?-and moves on to chapters on topics ranging from attachment and invasion of the respiratory tract to vaccine-induced immunity. The editors are leaders primarily in the areas of molecular biology and pathogenesis, and the focus of much of the book is on these topics, although issues such as treatment, carriage, disease in persons with immunodeficiencies, antimicrobial resistance, and epidemiology are also well covered. The relatively recent deciphering of several pneumococcal genomes has led to a new outburst of research activity, aspects of which are summarized in several of the chapters. 
All of the authors are recognized experts in their respective areas. The foreword by Robert Austrian, a pioneer in pneumococcal microbiology, disease description, and vaccine work, provides an interesting summary of the history of major discoveries in the field. While covering many areas of pneumococcal research, the book is not exhaustive; for example, issues specific to pneumococcal disease in developing countries are mentioned only in passing.

The book may be most suitable as a tool for new researchers in the pneumococcal field, but it may also be useful for medical students, graduate students, and infectious disease specialists. The level of detail varies among the chapters, but it is adequate to provide an introduction to each of the topics covered, and all chapters are thoroughly referenced. Overall, the editors and writers have done a remarkable job of consolidating the latest information. The Pneumococcus is an authoritative reference in a rapidly changing field.

\section{Cynthia G. Whitney*}

${ }^{*}$ Centers for Disease Control and Prevention, Atlanta, Georgia, USA

Address for correspondence: Cynthia G. Whitney, Respiratory Diseases Branch, Division of Bacterial and Mycotic Diseases, National Center for Infectious Diseases, Centers for Disease Control and Prevention, 1600 Clifton Rd NE, Mailstop C23, Atlanta, GA 30333, USA; fax: 404-639-3970; email: cwhitney@cdc.gov

\section{DNA Amplification: Current Technologies and Applications}

\section{Vadim V. Demidov and Natalia E. Broude, authors}

\section{Horizon Bioscience, Norfolk, UK IBSN: 0-9545232-9-6}

Pages: 335, Price: U.S.\$180

DNA amplification is a powerful technique that has had an immense impact on scientific research in the past 2 decades. While polymerase chain reaction (PCR) is still the most popular method, alternative methods of DNA amplification are constantly being developed. In addition, the extraordinary versatility of PCR has led to its use in novel ways that have opened new avenues of research. These novel methods for DNA amplification and the versatility of PCR are highlighted in DNA Amplification: Current Technologies and Applications.

The 17 chapters in this book are divided into 4 sections that focus on enzymes (3 chapters), thermal cycling methods (6 chapters), isothermal methods (6 chapters), and the detection of non-DNA analytes by DNA amplification (2 chapters). Each chapter has a thorough description of methods and highly detailed protocols for applying the technique to at least 1 specific application. Several excellent chapters describe the uses of Phi29
DNA polymerase and of applications using isothermal rolling circle amplification. A chapter on multiple-displacement amplification details the isothermal amplification of total genomic DNA and should prove extremely useful for amplifying DNA in limited amounts, such as DNA from clinical samples. The final 2 chapters describe use of either realtime PCR or rolling circle amplification to detect and quantify non-DNA analytes, such as serum cytokines, with much greater sensitivity than conventional enzyme-linked immunosorbent assay methods.

This book is not for the novice scientist, as it does not describe basic DNA amplification fundamentals; rather, it is directed at those with a solid background in molecular biology who desire knowledge of cuttingedge applications. Although many of the detailed protocols will not be applicable to certain laboratory situations, the versatility of most of the methods described will allow them to be easily adapted to other studies. Therefore, this book will be a good addition to the library of researchers in molecular biology or to molecular diagnostics laboratories planning to expand their horizon beyond standard PCR amplification techniques.

\section{Robert F. Massung*}

*Centers for Disease Control and Prevention, Atlanta, Georgia, USA

Address for correspondence: Robert F. Massung, Centers for Disease Control and Prevention, 1600 Clifton Rd, Atlanta, GA 30333, USA; fax: 404-639-4436; email: rfm2@cdc.gov

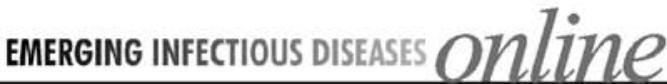

\section{WWW.cdc.gov/eid}

To receive tables of contents of new issues send an email to listserve@cdc.gov with subscribe eid-toc in the body of your message. 